\title{
SUPRACONDYLAR FRACTURE IN CHILDREN TREATED BY CLOSED REDUCTION AND INTERNAL FIXATION WITH K-WIRES
}

\author{
Pereddy Somashekhara Reddy', Subhash Ushakoyala ${ }^{2}$ \\ ${ }^{1}$ Associate Professor, Department of Orthopaedics, Apollo Institute of Medical Sciences and Research Center, Apollo Health City, \\ Hyderabad. \\ 2Senior Resident, Department of Orthopaedics, Apollo Institute of Medical Sciences and Research Center, Apollo Health City, \\ Hyderabad.
}

\begin{abstract}
During the period of December 2012 to July 2013, 30 children with displaced supracondylar fractures of humerus were treated by closed reduction and percutaneous crisis-cross K-wire fixation. The technical details of the procedure include.(1) reduction under general anaesthesia with adequate relaxation.(2) insertion of crossed K-wire under image intensifier control to determine adequacy of reduction. By Mitchell and Adam's criteria acceptable results were obtained in 28 out of thirty cases studied. Two results were unacceptable because of loss of flexion of $30^{\circ}$ and $20^{\circ}$ respectively; moreover one of these patients developed postoperative ulnar nerve injury also. There were two cases who presented with absent radial pulse both of them recovered after emergency reduction and pinning without long term sequel. This is a safe and reliable technique for obtaining and maintaining an excellent reduction in this difficult fracture.
\end{abstract}

\section{RESULTS}

Supracondylar, Fracture, Pinning, K-wire Fixation.

HOW TO CITE THIS ARTICLE: Reddy PS, Ushakoyala S. Supracondylar fractures in children treated by closed reduction and internal fixation with K-wires. J Evolution Med Dent Sci 2016;5(2):135-140, DOI: 10.14260/jemds/2016/33

\section{INTRODUCTION}

Supracondylar fracture of humerus is one of the commonest fractures sustained by children.1,2,3,4 Supracondylar fracture of humerus is the commonest fracture around the elbow in children accounting for $50 \%$ to $70 \%$ of fractures in this region.5,6 The rate of occurrence increases steadily in the first five years of life to peak at 5-7 years of age.

The management of displaced supracondylar fracture of the humerus is one of the most difficult of the many fractures seen in children.

Pitfalls in the management occur frequently and continue to trouble the doctor caring for these patients, especially with respect to displaced supracondylar fractures.

If the fracture is not treated properly it may give rise to many complications like Volkmann's ischemic contracture, Neurovascular injury, Skin slough, Myositis Ossificans, Elbow stiffness and malunion.

There is no controversy about management of the nondisplaced fractures. But many methods have been proposed for the treatment of displaced supracondylar fractures of the humerus in children, such as Closed Reduction and Plaster of Paris slab application, Skin Traction, Overhead skeletal traction, Open reduction and Internal fixation and Closed Reduction and Percutaneous Pin Fixation.

Closed reduction with plaster of Paris slab immobilization has traditionally been recommended for

Financial or Other, Competing Interest: None.

Submission 18-12-2015, Peer Review 19-12-2015,

Acceptance 02-01-2016, Published 06-01-2016.

Corresponding Author:

Pereddy Somashekhara Reddy,

Associate Professor, Department of Orthopaedics, AIMSR,

Apollo Health City, Jubilee Hils, Hyderabad.

E-mail: drpereddysr@gmail.com

DOI:10.14260/jemds/2016/33 displaced supracondylar fractures, but loss of reduction and necessity of repeated manipulation is likely to go for malunion producing varus or valgus deformity of elbow and elbow stiffness.

Traction (Skin or skeletal), which has also been used for many years, has been shown to be safe and reliable, but it has the drawback of requiring a long stay in the hospital.

Open reduction and Internal fixation has generally been reserved for specific indications mainly for an open fracture, a fracture requiring vascular exploration or an irreducible fracture.

Recent studies have shown good functional results with closed reduction and percutaneous fixation using ' $\mathrm{K}$ ' wires and are the most commonly accepted treatment of displaced supracondylar fractures of the humerus in children.

Much attention has been paid to the problem of malunion of supracondylar fractures of humerus by obtaining as anatomical reduction as possible by closed method because it is no longer acceptable to hear: "Not bad for a supracondylar fracture of Humerus". ${ }^{7}$

This study has been undertaken to observe the results of management of supracondylar fractures in children by closed reduction and percutaneous K-wire fixation. Patients selected for this study were children below 14 years with Gartland's type II and III fractures who were admitted and treated during the period from Dec 2012 to July 2013.

\section{AIMS AND OBJECTIVES}

AIM

- To study the demographic features and outcomes of supracondylar fractures in children treated by closed reduction and internal fixation with $\mathrm{K}$-wires. 


\section{OBJECTIVES}

1) To study the incidence of supracondylar fracture humerus in children in terms of,

- Age

- Sex

- Side

- Type of fracture

- Type of displacement and

- Associated injuries

2) To evaluate functional and anatomical outcome, of supracondylar fracture humerus in children treated with closed reduction and internal fixation with $\mathrm{K}$-wires in terms of,

- Duration of hospital stay.

- Postoperative complications.

- Flexion loss.

- Change in carrying angle.

\section{HISTORY AND REVIEW OF LITERATURE}

In 3rd and 4th century B.C., HIPPOCRATES mentioned in his work of fracture and dislocations "SENEX DIVINUS" about treating supracondylar fracture of humerus in position assumed during the rise of javelin or a bow.

SHIM, JONG, et al. (2002) treated this fracture with three percutaneous pin fixation; two laterally and one medially. He advised fixing this fracture with two lateral pins first allows elbow to be extended for safe placement of medial pin. ${ }^{8}$

PARIKH SN, et al. (2004) noted that pinning is not necessary for all type 2 supracondylar fractures and suggested that an attempt at closed reduction and casting with selective pinning of the fractures which lose position is a justified approach. ${ }^{9}$

DEVANANI AS (2005) recommends gradual reduction of supracondylar fractures which presents late, followed by correction of unacceptable deformity by an osteotomy. ${ }^{10}$

CHEN W (2010) conducted 203 cases of retrospective analysis of complications of supracondylar fractures of humerus in children and concluded that early reduction is the key for prevention of further vascular injury, nerve injury and osteofascial compartment syndrome. Operation is essential when expectant treatment is invalid. Satisfactory reduction, good fixation and functional rehabilitation are key points for preventing cubitus varus deformity. ${ }^{11}$

\section{METHODOLOGY}

The clinical material for the study, "Surgical management of supracondylar fractures of humerus in children with Kirschner's wire fixation," consists of 30 cases of fresh supracondylar fractures of humerus in children of traumatic etiology meeting inclusion and exclusion criteria, admitted to Apollo Group Hospitals, Jubilee Hills, Hyderabad, AP, in the time period between Dec 2012 to July 2013.

\section{Inclusion Criteria}

1. Fresh Gartland type II and type III fractures.

2. Age less than 14 years.

3. Supracondylar fractures with or without neurovascular complication.

\section{Exclusion Criteria}

1. Gartland type I fractures.

2. Mal-united fractures.

3. Fractures more than 2 weeks' old.

\section{STUDY PROFORMA}

As soon as the patient was admitted, a detailed history was taken and a meticulous examination of the patient was done. The required information was recorded in the study proforma.

The patients radiograph was taken in antero-posterior and lateral views. The diagnosis was established by clinical and radiological examination.

In this study, supracondylar fracture of humerus was classified according to Gartland's classification.

Temporary closed reduction was done on admission and above elbow posterior pop slab was applied in $90^{\circ}$ of flexion at elbow. The limb was elevated to reduce swelling of the elbow.

All patients were taken for elective surgery as soon as possible after necessary blood, urine and radiographic preoperative work-up. therapy.

All patients were started on prophylactic antibiotic

\section{OPERATIVE TECHNIQUE}

Closed reduction followed by stabilization with K-wires. Technique of Closed Reduction

Longitudinal traction with elbow in extension and supination was given. At the same time counter traction was given by an assistant by holding proximal portion of arm.

Continuing traction and counter traction, medial or lateral displacement were corrected by valgus or varus force respectively at fracture site.

After that posterior displacement and angulation was corrected by flexing the elbow and simultaneously applying posteriorly directed force from anterior aspect of proximal fragment and anteriorly directed force from posterior aspect of distal fragment.

If an adequate reduction is obtained the elbow should be capable of smooth and almost full flexion. Confirm the adequacy of reduction under image intensifier in two views.

1. Antero-posterior view or Jone's view.

2. Lateral view by externally rotating the arm.

After getting satisfactory alignment reduction was maintained by percutaneous K-wire fixation.

After experiencing failure to obtain a satisfactory reduction after two or three manipulations, we consider open reduction.

\section{Introduction of K-wires}

Stainless steel Kirschner's wire of about $1.2 \mathrm{~mm}$ to $2.0 \mathrm{~mm}$ were used.

We used two criss-cross pins, one from medial epicondyle and one from lateral condyle. After achieving satisfactory reduction by closed technique, K-wires were introduced with the help of a power drill under image intensifier control.

$\mathrm{K}$-wire placement was checked in image intensifier in antero-posterior and lateral views.

\section{Post-operative Management}

Post-operatively, operated limb was elevated on a drip-stand and patient was encouraged to move fingers.

$\mathrm{K}$-wires were removed at 3 weeks post-operatively after X-ray confirmation of satisfactory callus formation. Pop splint was discarded at the same time and patient was encouraged to do active elbow flexion-extension and supination-pronation exercises. 
Patients were advised not to lift heavy weight till 12 weeks post-operatively.

Follow-up was done on OPD basis at $3^{\text {rd }}$, 6th and 12th week post-operatively. The followup was done by clinical and radiological evaluation, and results were assessed based on:
1. Pain.
2. Swelling.
3. Tenderness at fracture site.
4. Movements of the elbow.
5. Carrying angle of the elbow compared with normal.
6. Union of the fracture.
7. Bauman's angle.

\section{CASE 1}
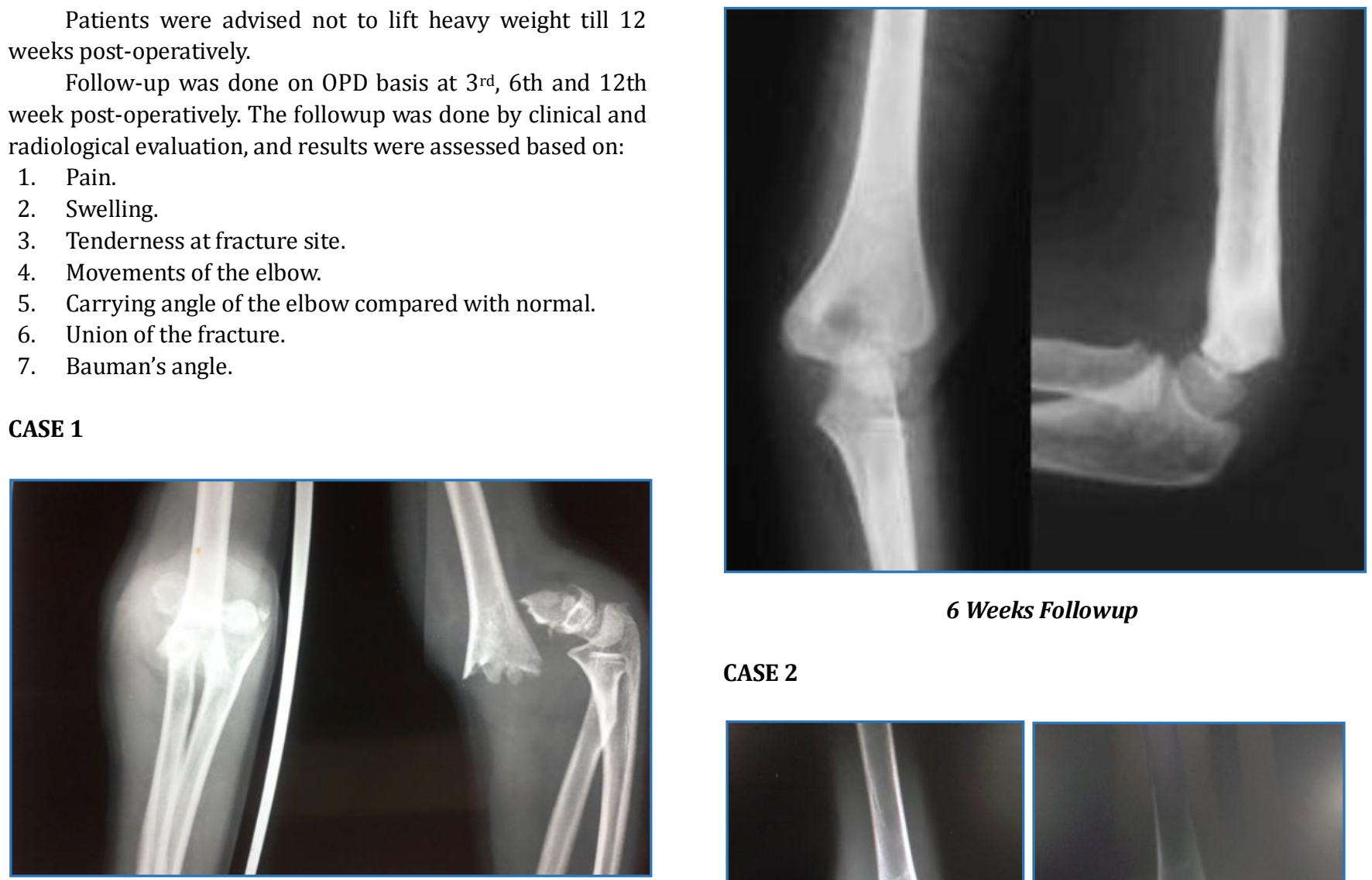

\section{Weeks Followup}

\section{CASE 2}
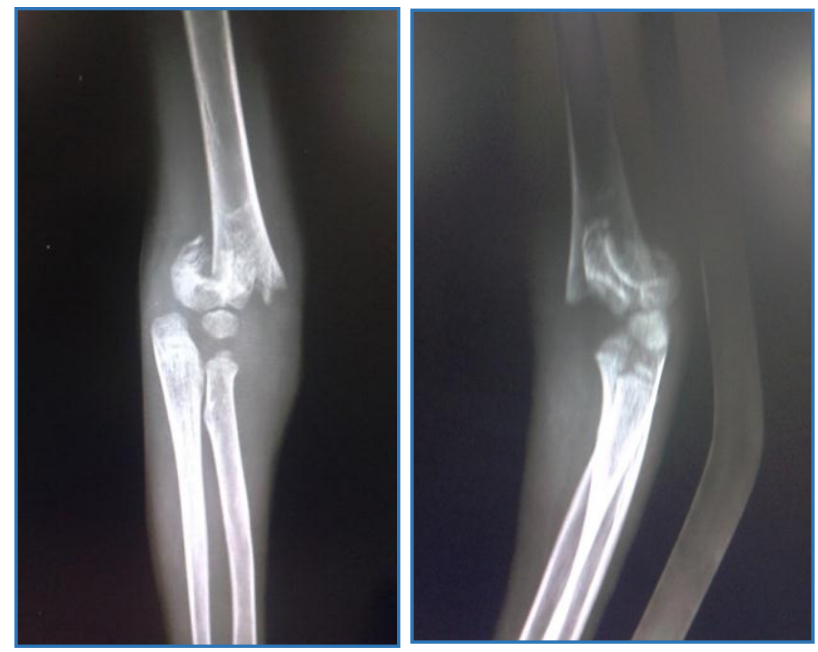

Pre-Operative

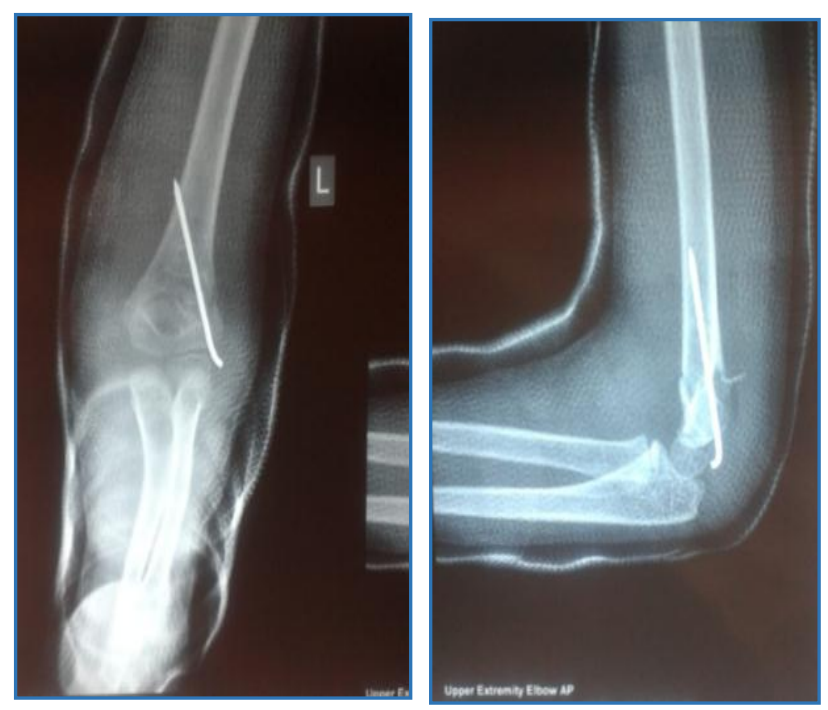

3 Weeks Followup

Post-Operative 


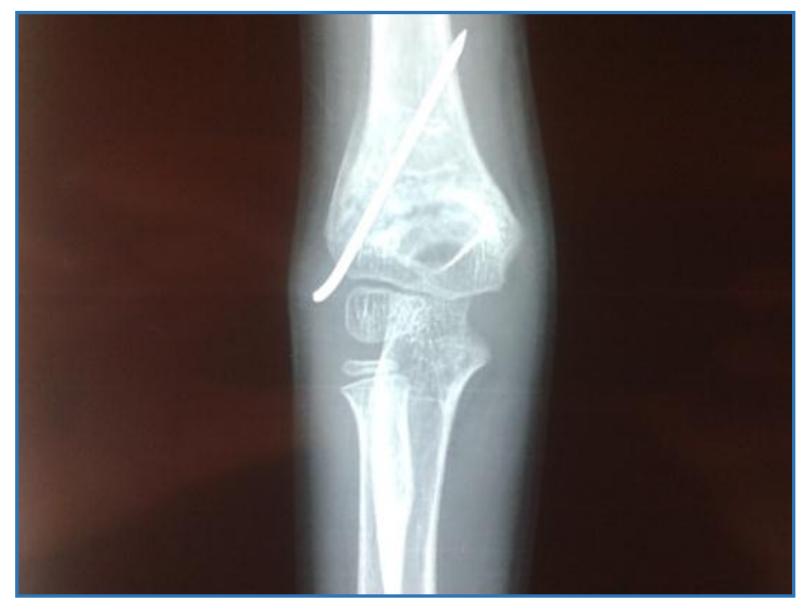

6 Weeks Followup

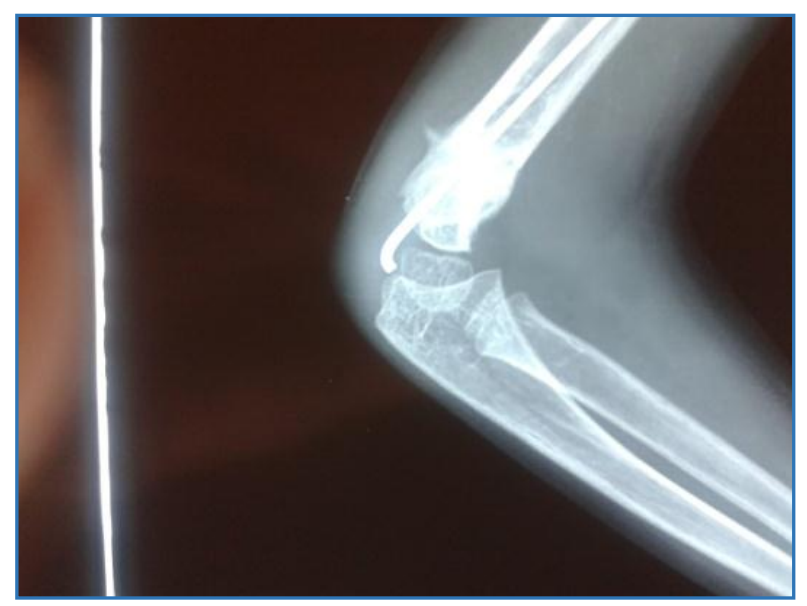

AP 6 Weeks Followup-Lateral

\section{OBSERVATIONS}

The following observations were made in the present study.

\section{DEMOGRAPHIC FEATURES}

AGE

The age of the patient in the study, ranged from 2 years to 13 years average being 7.06 years.

\section{SEX}

In the study, out of thirty patients, twenty were males and ten were females.

\section{SIDE OF INJURY}

In the study of the thirty patients, eleven had an injury of right humerus and other nineteen had injury of left humerus.

\section{TYPE OF FRACTURE}

Among thirty patients in the study, only one patient had flexion type of supracondylar fracture, remaining all twenty nine patients had extension type of fracture.

\section{DISPLACEMENT}

In thirty cases included in this study; twenty two patients had posteromedial displacement and seven patients had posterolateral displacement.

The only flexion type of fracture was displaced Anterolaterally.

\section{ASSOCIATED INJURIES}

Among thirty patients, two patients had radial nerve palsy and one patient had median nerve palsy. Nerve injury in all these three patients recovered spontaneously by the time fracture healed (6-8 weeks).

We came across two brachial artery injury in this study in the form of absent radial artery pulsation. Both of which improved after emergency closed reduction and percutaneous pin fixation.

\section{PINNING METHOD}

Of 30 cases, 17 of them underwent 2 cross wired pinning, 7 of them underwent 2 wire lateral pinning and 6 of them underwent 3 wire pinning.

\section{FUNCTIONAL OUTCOMES DURATION OF HOSPITAL STAY}

In this study, total duration of hospital stay ranged from 3 days to 5 days. Average is 3.66 days.

\section{POSTOPERATIVE COMPLICATIONS}

Among thirty cases of supracondylar fractures operated, we encountered ulnar nerve injury in two patients both of them recovered spontaneously within twelve weeks.

Pin tract infection occurred in three patients which were satisfactory union of fracture, all pin tract infections healed without any adverse effect on fracture healing.

Two patients in the study developed cubitus varus, which possessed cosmetic problem as both patients had good functional range of elbow motion.

\section{LOSS OF FLEXION}

Among these thirty cases, loss of flexion ranged from zero degrees to sixty degrees, the average being 7.33 degrees.

\section{CHANGE IN CARRYING ANGLE}

Among these thirty cases on follow up, change in carrying angle ranged from zero degree to nine degrees, the average being 3.47 degrees.

In two patients carrying angle was not calculated due to Fixed Flexion Deformity (FFD) of elbow.

\section{RESULTS}

In the present study, thirty cases of supracondylar fracture of humerus were treated by K-wire fixation and results were evaluated according to Mitchell and Adams criteria. Among thirty patients twenty four (80\%) patients had excellent result, four patients $(13.33 \%)$ had good result, while two patients $(6.66 \%)$ got poor result.

\begin{tabular}{|c|c|c|}
\hline RESULTS & $\begin{array}{c}\text { NUMBER OF } \\
\text { PATIENTS }\end{array}$ & $\begin{array}{c}\text { PERCENTAGE } \\
\text { (\%) }\end{array}$ \\
\hline EXCELLENT & 24 & $80.00 \%$ \\
\hline GOOD & 04 & $13.33 \%$ \\
\hline POOR & 02 & $06.66 \%$ \\
\hline \multicolumn{3}{|c|}{ Table 1 } \\
\hline
\end{tabular}

The results in this study are well comparable to previous studies. The mean of percentage of satisfactory results of previous studies is 84.7 . The percentage of satisfactory results in present study is $93.33 \%$. 


\begin{tabular}{|c|c|c|c|}
\hline SERIES & YEAR & $\begin{array}{c}\text { PERCENTAGE OF } \\
\text { SATISFACTORY } \\
\text { RESULTS }\end{array}$ & $\begin{array}{c}\text { PERCENTAGE OF } \\
\text { UNSATISFACTORY } \\
\text { RESULTS }\end{array}$ \\
\hline $\begin{array}{c}\text { FOWLES et } \\
\text { al. }\end{array}$ & 1974 & $87.5 \%$ & $12.5 \%$ \\
\hline $\begin{array}{c}\text { NACHT et } \\
\text { al.6 }\end{array}$ & 1983 & $76 \%$ & $24 \%$ \\
\hline $\begin{array}{c}\text { ARONSON } \\
\text { \& PRAGER } \\
\text { et al. }\end{array}$ & 1987 & $100 \%$ & $20 \%$ \\
\hline $\begin{array}{c}\text { PIRONE et } \\
\text { al. }{ }^{2}\end{array}$ & 1988 & $80 \%$ & $20 \%$ \\
\hline $\begin{array}{c}\text { DAVIS et } \\
\text { al. }\end{array}$ & 2000 & $80 \%$ & $6.6 \%$ \\
\hline $\begin{array}{c}\text { Present } \\
\text { study }\end{array}$ & 2012 & $93.33 \%$ & Table 2 \\
\hline \multicolumn{3}{|c|}{} \\
\hline
\end{tabular}

The mean percentage of satisfactory results derived from other series -84.7, and the mean percentage of the same in our study is-93.33. Our study results have better outcome than other series.

\section{DISCUSSION}

Supracondylar fractures of the humerus are one of the commonest injuries in children. Unfortunately, it is one of the more difficult fractures to treat.

Difficulty in treating this fracture lies in the fact that the fracture gets complicated very often, moreover some of the complications are of nature, which threatens optimal use of the extremity either temporarily or permanently.

Initial treatment as well as definitive treatment of this fracture is of utmost importance. This is quite often complicated in developing countries like India due to lack of awareness, poverty and presence of traditional bonesetters.

Percutaneous Kirschner's wire fixation for supracondylar fracture of humerus in children offers simple, safe and affordable treatment option.

Thirty cases of supracondylar fractures of humerus in children were treated by closed reduction followed by percutaneous K-wire fixation in this study. The purpose of the study is to evaluate the outcome of management of supracondylar fracture of humerus in children by K-wire fixation.

The data collected in this study is assessed, analysed, compared with other series and results were evaluated.

\section{CONCLUSIONS}

In the present study, thirty patients with supracondylar fracture of humerus in children were managed surgically with percutaneous Kirschner's wire fixation. The data was assessed, analysed, evaluated and the following conclusions were made:

- Supracondylar fractures of humerus are common in children due to anatomical characteristics of distal end of humerus and elbow in this age group.

- Supracondylar fractures of humerus are more common in boys than girls probably due to more activity in boys.

- Supracondylar fracture of humerus in children is more common in left side than right side.

- The most common mode of injury for supracondylar fractures of humerus is fall on an outstretched hand, which results in extension type of fractures. Flexion type of fracture is rare.
- Most common type of displacement is poster medial compared to postero-lateral displacement. Anterior displacement is rare.

- Most common associated nerve injury with posteromedial displacement is Radial Nerve injury.

- Most common associated nerve injury with posterolateral displacement is Median Nerve injury.

- Rigid fixation is achieved by two or three Kirchner's wire fixation put through medial epicondyle and lateral condyle or through lateral epicondyle.

- The period of hospital stay is short. Average duration of hospital stay is 3.66 days.

- Majority of patients regained full range of flexion, i.e. less than ten degrees of flexion loss. Three patients had flexion loss between ten degrees and twenty degrees. Two patients had loss of flexion more than twenty degrees. Average loss of flexion in this study was 7.33 degrees.

- In this study, difference in carrying angle of injured with uninjured elbow ranged from zero degree to nine degrees. Average change in carrying angle was 3.47 degrees.

- Two patients developed cubitus varus deformity. In both cases it is of cosmetic concern only as both cases has gained good range of elbow motion.

- In this study, results were evaluated according to Adam's and Mitchell's (1961) criteria. According to this criteria, in this study twenty four patients $(80 \%)$ had excellent, four patients $(13.3 \%)$ had good and two patients $(8.8 \%)$ had poor results.

- The method is simple, safe and effective. The period of hospital stay is short, which makes this method very economical.

- With this technique, consistently satisfactory results can be obtained both cosmetically and functionally.

- $\quad$ By this method, we have achieved early mobilization of the elbow with good range of elbow movement with fewer complications.

\section{BIBLIOGRAPHY}

1. David DA, Bruce IP. Supracondylar fractures of humerusa modified technique of closed pinning. CORR 1987;219:174-184.

2. Pirone AM, Graham HR, Krajbich JI. Management of displaced extension- type supracondylar fractures of the humerus in children. JBJS 1988; 70-A(5):641-650.

3. Hamid RM, Charles S. Crossed pin fixation of displaces supracondylar humerus fracture in children. CORR 2000;376:56-61.

4. James RK, James HB. Rock wood Green's fracture in children. 5th ed. Lippincot Williams \& Wilkins, 2001.

5. John AH. Tachdjian's pediatric orthopedic. 3rd ed, Saunders; 2002.

6. Jeffery LN, Malcom LE, Stanley MK, et al. Supracondylar fractures of humerus in children treated by closed reduction and percutaneous pinning. CORR 1983;177:203-209.

7. Canale TS. Campbell's operative orthopedics. 10th ed. Mosby; 2003. 
8. Shim JS, Lee VS. Treatment of completely displaced supracondylar fracture of the humerus in children by cross-fixation with Kirschner's wire. JP02002;22(1):12-6.

9. Parikh SN, Wall EJ, Foad S, et al. Displaced type II extension supracondylar humerus fracture: do they all need pinning? J P 0 2004;24(4):380-4.
10. Devanani AS. Late presentation of supracondylar fracture of the humerus in children. CORR 2005;431:36-41.

11. Chen W - Zhongguo Xiu Fu Chong Jian Wai Ke Za Zhi. Retrospective analysis of complications of supracondylar fracture of humerus in children. - 01-Mar2010;24(3):315-832. 